\title{
Personalized Course Recommendation System using Deep Learning
}

\author{
Deepali Vora, Shonal Londhe
}

\begin{abstract}
Recommender Frameworks are a regular examinations this is applied in stand-out areas. course concept is taken into consideration as a tried location that has not been tested absolutely. It blessings college understudies who want thought and similarly improves manner resolve administrative work for the length of the pre-enlistment span. a prime scope of the understudies do various distributions to enhance their reputation diploma. Be that as it is able to, the huge lion's percentage of the understudies don't understand which heading need to be taken first and after that later. The recommender structures made will assist understudies in highlighting slight productions basically as decreasing time to study guides in an effort to be taken. The proposed machine will reflect onconsideration on the benefactor tendency and guarantee that the productions directed are of their advantage and region. Understudies might not be capable see, proper heading as tested thru their little bit of leeway and region in which they could take into account.
\end{abstract}

Watchwords-idea structures, KNN, LSTM, fake Neural gadget.

\section{ADVENT}

the same old route of motion of picking productions to do research paintings is a dreary, perilous and dull endeavor that fundamentally affects the show however the thinking about basis of a grasp as properly. As such, selecting attending to be directs in real years need to do ask kind of in a most important way. each understudy has assorted needs with recognize to inspecting. it's going to in wellknown be tough to pick which manner is awesome to take gaining ground towards starting, and which teacher will great match as a mess around the understudy's turning into more familiar with design [1].

the important thing difficulty for the overall understudy is they want modified get phase to data situation to the dispositions and requirements. to conquer this difficulty Recommender Frameworks (RS) are used that separates the statistics thusly in line with the purchaser miens and a greatest slight one is blanketed an big space of capability subjects. To customise records, recommender systems are used both to look a tantamount purchaser or to realize notable gadgets of the consumer's boom [2]. Recommender Frameworks composed the information, related to issues and offers the patron some distance reaching proposition as indicated via their advantage. Recommender Frameworks are a subset of information keeping apart notion having the capability to assist clients in making a man or woman

Revised Manuscript Received on 16 September, 2019.

Prof Deepali Vora, Department of Information Technology, Vidyalankar Institute of Technology, Mumbai, Maharashtra, India

(Email: deepali.vora@vit.edu.in)

Shonal Londhe, Department of Information Technology, Vidyalankar Institute of Technology, Mumbai, Maharashtra, India

(Email: shonal.vaz@vpt.edu.in) picking up gaining knowledge of of circumstance via spotting the most relevant and interesting problems from an full-size database by then propose it the supporter relying upon tendencies and pinnacle elegance. college direction dedication would possibly crush, mainly for understudies new to a product. the bigger the school, the extra noteworthy publications are given, and the more choices each understudy needs to make each semester. that allows you to get the extremely good larger part in their schooling and their scholarly cost, understudies take controls which can be pertinent to them, and that update their school association. normally, understudies need to select a direction, surprisingly large preparation (GE) course, in an workplace that is special to them [4].

on this situation, severa understudies want to take classes that engage them to maintain a prime element in their consideration on their middle examinations. those assistant making ready can be tough to pick out when understudies are new to the place of business in which they're given, especially thinking about the way that numerous teachers have exclusive methods to deal with area showing a comparable path. notwithstanding whether an understudy recognizes what type of heavenliness they're attempting to discover (e.G., a easy superbness, or one this is over the pinnacle pleasant and empowers the understudy to become acquainted with the office), notwithstanding all that they'll no longer recognize the correct way to take, or who to take it from. in this manner, an offer Framework is cherished. The component of all recommender structures is to present a proposition whilst in transit to be definitely surveyed and recognized via utilizing its clients.

The point of this examination creative creations is to shape and running up a part of and 1/2 Recommender shape that is probably facilitated to improve the sufficiency of any E-turning into more familiar with machine, to ease actualities get to and to provide personalization to understudies. The initial realizes this take a look at discover that the use of notion Framework to pick distributions performs well than regular methodologies [5].

Proposition structures are protected about get-collectively pertinent clues for the buyer. The purchaser, for this case, is an understudy, and the insights are the capacity guides to take. accumulating and placing actualities from one of a kind sources to make prized hints is a difficult trouble that severa concept systems challenge to illuminate.

This structure applies a hybrid proposal approach, the use of assorted capabilities stretching out from aides/educators' tests to the topic and passing charge with the concern form 


\section{Personalized Course Recommendation System using Deep Learning}

to make guidelines.

The rest of the paper consists of portion 2 Writing audit, stage 3 Proposed structure, section four Framework structure and phase five quit well-liked via References.

\section{II.LITERATURE OVERVIEW}

The composition assessment is enormous thinking about that:

- It depicts how the proposed examinations is related to earlier than look into in estimations.

- It indicates the creativeness and congruity of our evaluation difficulty. Remarkably, how

research is specific as regards to unique examiners.

- It legitimizes our proposed approach.

- It demonstrates the preparation to complete the research.

The desk 2.1 annexed diagrams the papers reviewed.

\section{III.INFERENCES}

information: From the evaluation of composing verify obviously the finished device would not reflect onconsideration on the primary situation, group of workers analysis, notoriety of the factors for exceptional understudies, take a look at shape of the situation (within the event that it slants nearer to step by step speculative or beneficial approach), the passing segment of the understudies in the given problem. This facts might be quantifiably bankrupt down and the yield of a similar is probably proven to the understudies difficulty to it. as a result of the quantifiable take a look at of this insights might also furthermore help with giving large tips to understudies.

- Algorithms:

non-stop information, similar to substance or time association has no memory related with the model. RNN addresses that difficulty thru together with a protest circle which fills in as a type of reminiscence. So the past commitments to the model leave an effect. LSTM widens that concept and via making both a blessing minute and an entire deal memory stage. in the end, LSTM is staggering tools for some thing that has a gathering. because the significance of a phrase relies upon upon the ones that went earlier than it. accumulating to-Succession LSTM models are the kingdom of the system for translations. They in like way have a vast bunch of uses like time affiliation sitting tight for which isn't commonly found out by using wonderful figurings.

Counterfeit neural frameworks have a surprising functionality of having importance from stuck or unfastened statistics. This limit might be used for secluding fashions and spotting patterns that are frustrated for laptop systems to get it. the key part of a faux neural system is the uncommon state of its records getting equipped device. This shape fuses of a large amount of considerably interconnected adapting to handling elements that depictions as one to attend to specific troubles. faux neural frameworks might be finished to an increasing assortment of true troubles of incredible capriciousness. they are used for dealing with inconveniences which can be absurdly astounding for everyday traits or the ones assortments of troubles that do not have an algorithmic association. while RNN has the accidents like Evaporating Inclination problem and likewise there may be difficulty of extending slants at each movement referred to as exploding points. It makes the coaching of RNN extreme, in selective strategies: (1) it can not technique lengthy groupings if the use of tanh as its activation paintings,

(2) it's far in truth shaky if the usage of relu as its authorization paintings.

$2 \mathrm{~d}$, it can't be stacked into outstandingly tremendous designs. [12]

\section{IV.PROPOSED FRAMEWORK}

The goal of proposed gadget is to improve a modern structure or to make a structure it's absolutely new and robust to the clients. The cause to manufacture a proposition gadget is profoundly treasured in assisting and dismantles within the clients to enter the locales, which can also in like way bring about developing buy trades of factors and further endowments. The proposed structure that's a course primarily based in reality notion gadget. The proposed device thinks roughly the main problem, assemblage of workers grumbling, pervasiveness of the factors for distinctive understudies, check out structure of the difficulty (at the off peril that it slants in the direction of gradually theoretical or planned approach), the passing phase of the understudies in the given problem. The proposed structure is anticipated to crush the inadequacies of past machine.

these all parameters are big in deciding on the ampleness or the popularity of the bearing that's to be taken via the understudies. The criticism of the instructors is concept about as a grasp contribution as they may understand what's incorporated into the path. Their evaluation is examined the use of the considerate check wherein the tokens of the data are taken all collectively that by way of using NeuroEtymological Programming NLP we can respect what are the insights of the teacher with admire to the heading material. The remainder of the parameters are taken from the past insights in which the structure will find out the predominance.

\section{V.SYSTEM DESIGN}

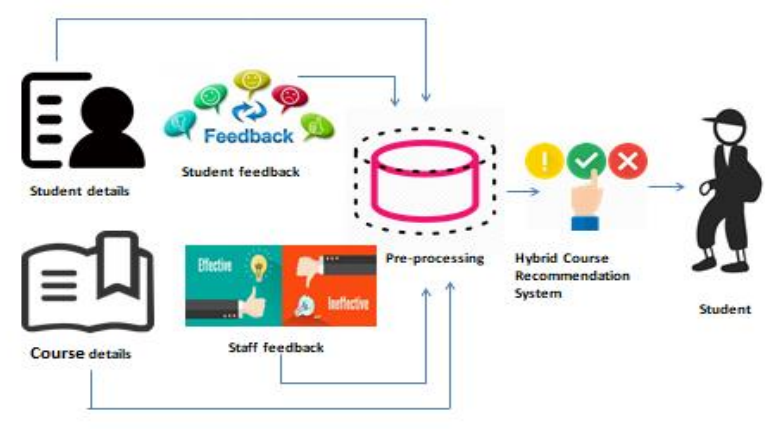

Figure1 : Proposed System Design

Published By:

Blue Eyes Intelligence Engineering

$\&$ Sciences Publication 
- $\quad$ student Subtleties: It incorporates of the critical insights of understudy like call, age, vicinity and goliath the center problem of the understudy nearby the interest. this will help the shape with prescribing the charmed course to understudy. [1][2][6]

- course Subtleties: It joins the insights across the heading and its destiny use inside the absolute programming. The parameters notion approximately for this is as according with the resulting:

1) approximately circumstance

2) period notably

three) graduation degree required to go to the bearing

4) body of workers complaint approximately bearing

5) Alumni enter roughly path

6) No of understudies taking announcement for way in beforehand of time years

7) Passing \% for prior years

eight) Pre-primary definitely

9) kind of hassle? green/Hypothetical

10) Passing hints speculation/useful

11) path versatility understudies could artwork be capable of low assurance/fulltime

12) faculty understudy share superbness period as an instance consumption for way

thirteen) monetary manual - produce for understudy award

14) sensible making ready give open entryways to their understudies to prepare palms on getting consolidating these in scholarly association (brief employment)

15) Laboratory look into

- $\quad$ scholar enter: It conveys differing evaluation for the path by methods for unique understudies. Following may be considered as the data parameters.

1) student enter

2) guides finished through utilizing understudy

3) Certifications finished through understudy

4) college students selected for grounds after this bearing [6]

- team of workers protest: It accommodates of contribution from institution of employees for the specific path. With the beneath statistics parameters:

1) college nuances who direct the direction year of appreciate, capability, input thru understudy

2) Qualification of work pressure

3) Books and paper distinctive with the aid of method for representatives

- Demographic nuances of Understudy: The understudy will enlist into the structure wherein they will enter all the pre-required nuances, as an instance, touch no, age, e mail, character nuances. The understudy will at that issue pick out the interior concern to get the thought. resulting to deciding on the middle difficulty, the understudies may be given guidelines reliant on the picked check, organization of employees input (which they'll have the selection to provide at whatever factor on the web site), No of past understudies placing off to the issue (popularity of the trouble), the significance of concept or businesslike within the take a look at, and the no of bypass rate implemented within the appraisal. [2][3]

- Pre-getting ready:
The facts is being gotten from various materials and is ready using clustering matter to form the game plan within the insights. [6]

- Hybrid route idea system:

The pre-organized data is then given as a commitment to the proposed device in which two or three figuring is being completed and after the careful assessment the path is been encouraged to the consumer. [5]

\section{VI.END\& RESULTS}

The proposed gadget for proposition will consider the patron propensities with unique parameters like input from organization of laborers which gives understudies the facts of the manner which they are taking. The end result indicated will give understudies legitimate danger to survey themselves and select the maximum extreme perfect direction for them.

This shape applies a hybrid proposition strategy, using distinct capabilities strolling from distributions/educators' exams to the issue and passing accuse of the circumstance shape to make hints.

This Recommender Framework will suggest and address an understudy in choosing the productions as regards to their critical. The half breed method has been applied along cosmology to get better valuable actualities and make express regulations. this type of device is likely superb to understudies to enlarge their creation and improve their prosperity arrange as well. The proposed recommender systems may want to perform higher thru directing the powerlessness of basic man or woman recommender systems.

The basic goal of the device is to overtake the modernday structure with the guide of pondering the crucial check, assemblage of laborers analysis, noticeable nice of the points for special understudies, look into shape of the check (at the off chance that it slants closer to step by step theoretical or to be had method), the passing phase of the understudies in the given take a look at. This measurements is probably quantifiably bad down and the yield of a similar might be tested to the understudies relying upon it. This structure will viably guarantee that the understudies get the proposition as close to their requirements.

\section{REFERENCES}

1. Kiratijuta Bhumichitr, Songsak Channarukul, Nattachai Saejiem, Rachsuda Jiamthapthaksin, Kwankamol Nongpong, "Recommender Frameworks for college non-obligatory path advice"14th standard Joint meeting on software program engineering and Programming building (JCSSE), 2017

2. Amer Al-Badarenah, Jamal Alsakran, "An Mechanized Recommender Framework for course selection" worldwide Diary of reducing edge software program engineering and packages,(IJACSA), Vol. 7, No. 3 , 2016

3. Jaimeel M. Shah, Lokesh Sahu, "A half and half put together notion Framework subordinate with respect to Bunching and association", Paired Diary of data Mining and systems administration five (2015) 


\section{Personalized Course Recommendation System using Deep Learning}

4. Jie Xu, Tianwei Xing, Mihaela van der Schaar "custom designed route Grouping guidelines", IEEE Exchanges on sign coping with, extent: sixty four , problem: 20 , Oct.15,2016

5. Ahmed Mohammed ok. Alsalama, "A 1/2 and 1/2 concept Framework depending on association policies", international Diary of computer and records Designing, Vol:9, No:1, 2015

6. Behdad Bankshinategh, Gerasimos Spanakis, Osmar Zaiane and Samira ElAtia, "A direction Recommender Framework relying upon Graduating Attributes", ninth international meeting on computer Upheld education, 2017

7. Jyoti Gupta, Jayant Gadge, "A structure for a proposal Framework dependent on Cooperative separating and Demographics", worldwide assembly on Circuits, Frameworks, Correspondence and information Innovation applications (CSCITA), 2014

8. Linqi Melody, Cem Tekin, and Mihaela van der Schaar, "net basically based totally getting to know in big scale relevant Recommender structures", IEEE Exchanges on Administrations Registering, quantity: nine , difficulty: three , may-June 12016

9. Chu, Y., Huang, F., Wang, H., Li, G., and Melody, X "non permanent idea With Repetitive Neural Networks", 2017 IEEE international meeting on Mechatronics and Mechanization (ICMA), 6-nine Aug. 2017

10. LIBO ZHANG, TIEJIAN LUO, FEI ZHANG, AND YANJUN WU," a proposal version depending on Profound Neural network", distributed in: IEEE access ( extent: 6 ), 05 January 2018

11. Li, S., Yan, Z., Wu, X., Li, An., and Zhou, B, "A approach for Enthusiastic exam of motion photograph dependent on Convolution Neural system and Bi-directional LSTM RNN", 2017 IEEE second time-honored meeting on information technological know-how inside the net (DSC), 26-29 June 2017

12. Gayatri Khanvilkar, Deepali Vora, "Enactment Capacities and preparing Calculations for Profound Neural network", global Diary of computer constructing in Exploration traits,2018.

Table2.1 Summary of review of papers

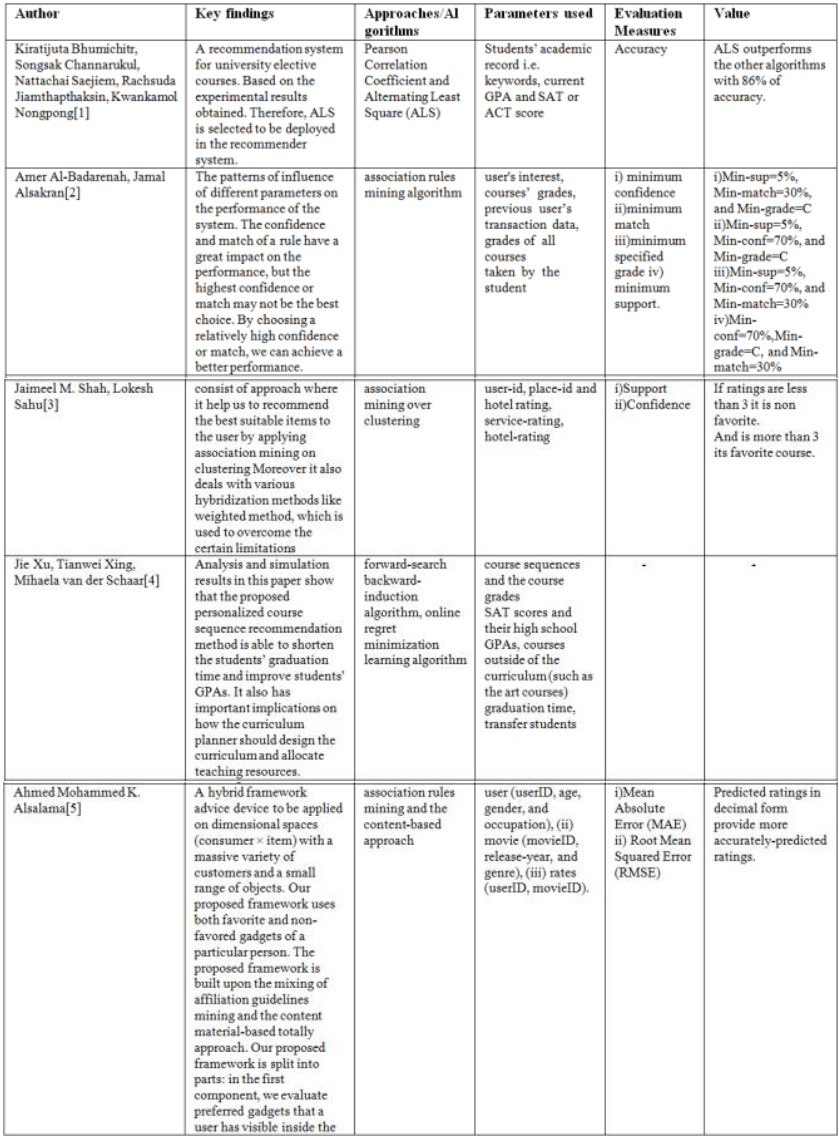

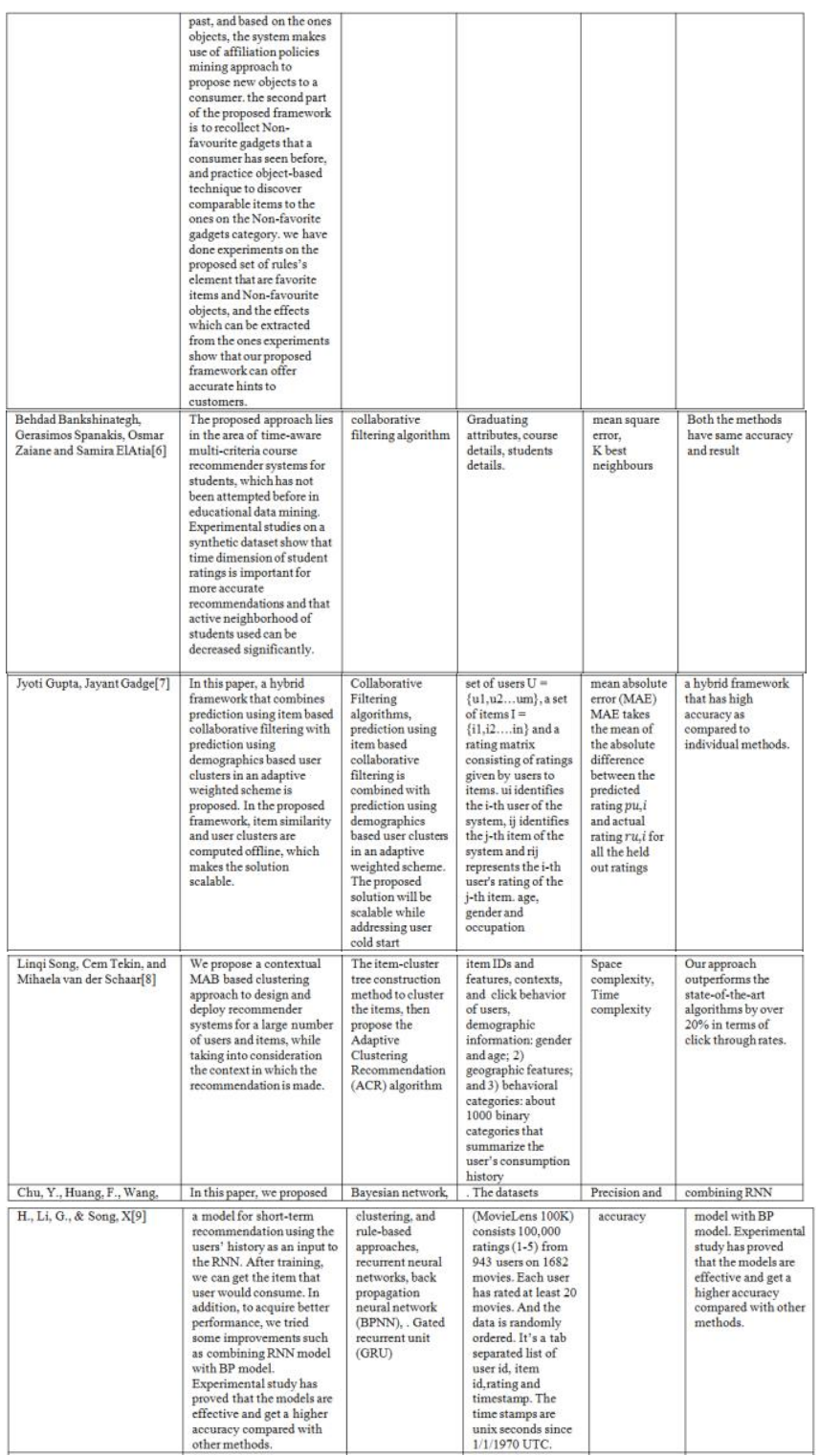




\begin{tabular}{|c|c|c|c|c|c|}
\hline $\begin{array}{l}\text { LIBO ZHANG. TIEIAN } \\
\text { LUO, FEI ZHANG, AND } \\
\text { YANUN WU[10] }\end{array}$ & 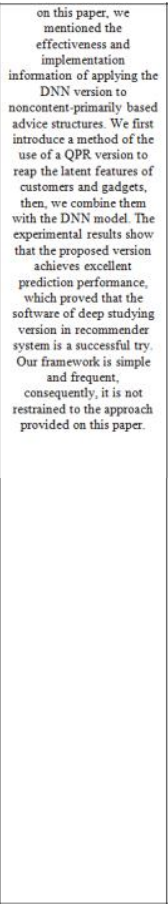 & 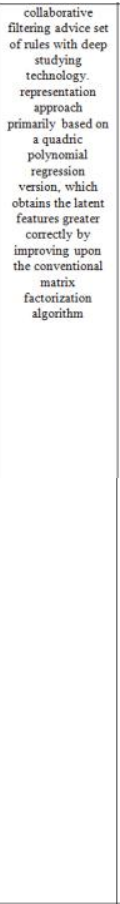 & 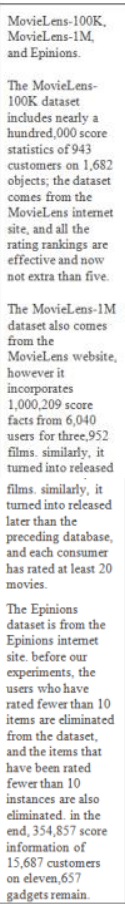 & \begin{tabular}{|c|} 
Mean \\
Absolute \\
Emor MAEE) \\
method and \\
the Root \\
Mean Squared \\
Error (RMSE) \\
method. \\
\end{tabular} & 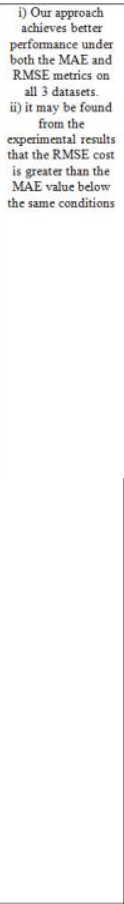 \\
\hline \multirow[t]{2}{*}{$\begin{array}{l}\text { Li, S., Yan, Z, Wu, X, Li, } \\
\text { A, \& Zhou, B[11] }\end{array}$} & $\begin{array}{c}\text { on this paper, we } \\
\text { recommend an emotional } \\
\text { evaluation technique } \\
\text { primanily based on } \\
\text { Convolution Neural } \\
\text { networth and Bi-directional } \\
\text { LSTM RNN. The model }\end{array}$ & $\begin{array}{c}\text { Convolution } \\
\text { Neural Network, } \\
\text { Bi-directional } \\
\text { LSTM RNN }\end{array}$ & $\begin{array}{c}\text { Movie reviews } \\
\text { marked positive or } \\
\text { negative. }\end{array}$ & 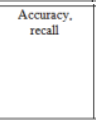 & $\begin{array}{l}\text { Improves the } \\
\text { accuracy by } \\
\text { combining } \\
\text { CNN+Bi+LSTM } \\
\text { instead of } \\
\text { individual. And it is } \\
\text { around }\end{array}$ \\
\hline & $\begin{array}{l}\text { improves the accuracy ys } \\
\text { compared to CNNN LSTM } \\
\text { and Bi-LSTM model. The } \\
\text { performance of the set of } \\
\text { rules may be very near the } \\
\text { modem-day perfomance } \\
\text { of conventional algonithms. }\end{array}$ & & & & $\begin{array}{l}\text { accuracy }=0.90061 \\
\text { Recall }=0.90194\end{array}$ \\
\hline
\end{tabular}

